\title{
SIMPÓSIO ALAGOANO DE ENGENHARIA CIVIL E SUAS CONTRIBUIÇÕES PARA O ESTADO E OS PETIANOS.
}

Ariana C. S. de Magalhães'; Ariany F. Cavalcante²; Diana M. P. Caires³;

Eduardo R. Neto"; José Matheus A. C. Alves5; Maria Clara L. Barbosa6;

Rayanne L. Barros ${ }^{7}$; Yanna P. de S. Siqueira ${ }^{8}$; Karoline A. de M. Moraes ${ }^{9}$.

1, 2, 3, 4, 5, 6, 7, 8, 9 Universidade Federal de Alagoas

Email do Autor: ariana.mmagalhaes@gmail.com

PET Engenharia Civil, Universidade Federal de Alagoas, Maceió, Alagoas

Palavras - chave: Palestra; ensino; evento; curso.

\section{Introdução}

O aprimoramento do trabalho em equipe e da organização interna, além da contribuição para uma formação sólida, com competências que vão além da academia, são apenas alguns dos benefícios que a organização de eventos e congressos trazem a um grupo PET e aos seus integrantes. É com esses objetivos que o PET Engenharia Civil da Universidade Federal de Alagoas (UFAL) planeja e executa a realização do SAEC, o Simpósio Alagoano de Engenharia Civil.

Sendo um agente de troca de ideias, compartilhamento de conhecimento e intercâmbio de experiências para os profissionais e estudantes da área. 0 SAEC vem como uma maneira de "garantir aos alunos do curso oportunidades de vivenciar experiências não presentes em estruturas curriculares convencionais" (Manual de Orientações Básicas - MOB, 2006), portanto, ele se caracteriza como uma atividade de extensão do programa.

O evento é totalmente organizado pelo PET Engenharia Civil, desde o planejamento inicial, a escolha da programação, palestrantes, meios de divulgação e patrocínio; até a execução propriamente dita do evento. O grupo 
se divide inicialmente em quatro equipes internas: comunicação, patrocínio, palestrantes e comitê científico; e, posteriormente, algumas equipes são extintas para inclusão de outras, em função das demandas que surgem durante o evento, como coffee-break, inscrições e infraestrutura.

Têm-se como objetivos do evento: congregar os estudantes de Engenharia Civil das diversas instituições de ensino do estado, assim como profissionais da área; promover debates sobre novas tendências implantadas no âmbito da Engenharia Civil; e ressaltar a importância dessa área de atuação para o desenvolvimento do país. Com isso, obtém-se uma expansão do acervo técnico da engenharia no estado e aumento da capacidade de inovação. Também se espera como benefício a divulgação do Programa de Educação Tutorial e os frutos por ele gerados na Universidade e para a sociedade como um todo.

Assim, vê-se que o SAEC é uma forma de "integrar os conhecimentos adquiridos pelas pesquisas à extensão e ensino, isto é, transformar um conhecimento em algo produtivo para a universidade e a sociedade" (GLANSO, 2007, p. 2).

\section{Objetivos}

Os objetivos deste trabalho são: apresentar o histórico, execução e impactos do SAEC, organizado pelo PET Engenharia Civil da Universidade Federal de Alagoas, divulgando a atividade e os benefícios para os petianos, como uma oportunidade de troca de experiências.

\section{Metodologia}

O presente trabalho foi elaborado com base nos relatos de petianos, portfólios, relatórios, sites e fotos das oito edições do SAEC. Inicialmente foram reunidos os documentos e arquivos citados, utilizando-os para a concepção e organização do trabalho e revisados de modo a obter dados e resultados para a formulação da pesquisa. Adicionalmente foram colhidos os relatos dos petianos para enriquecer a troca de experiências que o trabalho propõe. Desta forma, espera-se alcançar os objetivos supracitados, a fim de efetivar a divulgação da experiência na organização do evento e o formato do mesmo. 


\section{Resultados e Discussão}

O surgimento do SAEC, por iniciativa dos membros do PET Engenharia Civil da UFAL, se deu da necessidade que o Estado de Alagoas tinha de possuir um espaço para um debate amplo voltado à Engenharia Civil. Também foi um dos objetivos da criação do evento, a disseminação de tecnologias, inovações e informações sobre o setor de engenharia do Estado. Já foram realizadas oito edições do SAEC, tendo no ano de 2015 o maior número de participantes, como se observa no gráfico 1. Em média, o evento contou com 400 participantes por edição e ao longo dos anos vem se consolidando como 0 maior evento da área no estado.

Gráfico 1 - Quantidade de participantes do SAEC ao longo das edições.

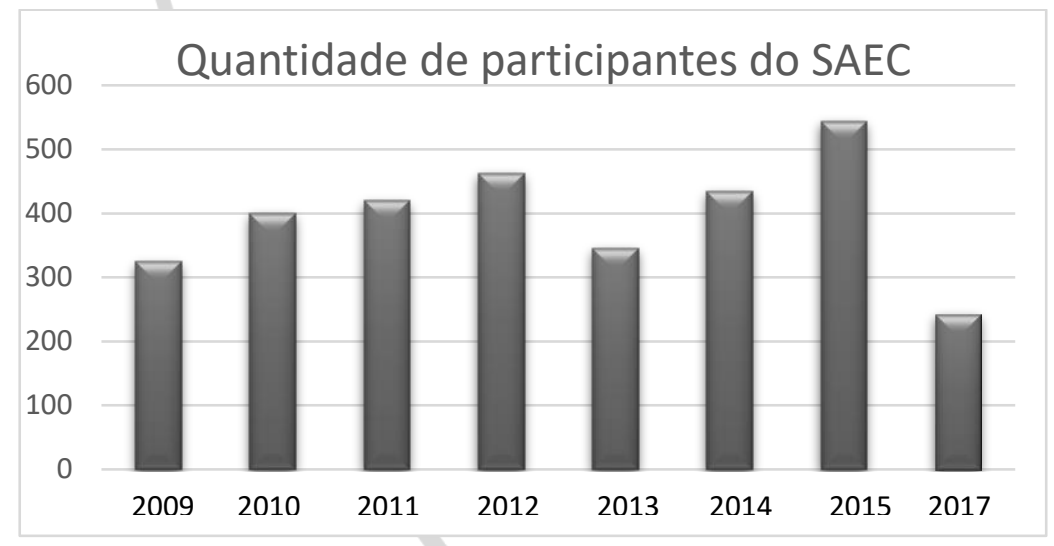

Fonte: Autores (2018)

Desde sua primeira edição o evento conta com palestras e mesas redondas em sua programação. Essas atividades, assim como o corpo de palestrantes, que sempre conta com professores e profissionais de todo o Brasil, são pensados a partir das necessidades acadêmicas e do mercado do estado de Alagoas. A ideia é sempre levantar assuntos de interesse do estado, a fim de que os debates que ocorram no evento contribuam para o desenvolvimento social, científico, tecnológico e financeiro aos participantes do evento, observando o Manual de Orientações Básicas - MOB que prevê como sendo um dos objetivos do PET.

Um exemplo do fomento desse tipo de debate foi a mesa redonda apresentada na última edição do evento intitulada "A gestão de competências na formação do novo engenheiro", figura 01 , vista a necessidade de os jovens engenheiros 
estarem cada vez mais preparados para o mercado, que se tornou mais competitivo em virtude da crise econômica enfrentada pelo país. A ideia da mesa foi expor diferentes pontos de vista sobre a formação do perfil requerido atualmente para os egressos do curso de Engenharia civil em Alagoas e no Brasil. Assim houve a fala de recrutador de $\mathrm{RH}$, jovens engenheiros e professores, que expuseram como a universidade prepara o aluno para 0 mercado de trabalho e as limitações encontradas no processo de formação.

Outra parte da programação do SAEC inclui a publicação e apresentação de trabalhos, figura 02, que efetiva a divulgação científica do conhecimento produzido no estado e regiões próximas. A submissão de trabalhos é dividida atualmente em duas categorias: "Trabalho científico" e "Trabalho científico com inovação tecnológica”. As categorias são premiadas separadamente e a ideia é dar destaque às inovações que estão sendo criadas e podem ser aplicadas na Engenharia Civil. Além dessas atividades, o SAEC conta com cursos e apresentação de estandes de interesse do público.

Figura 01 - Mesa redonda do VIII SAEC e apresentação de trabalhos

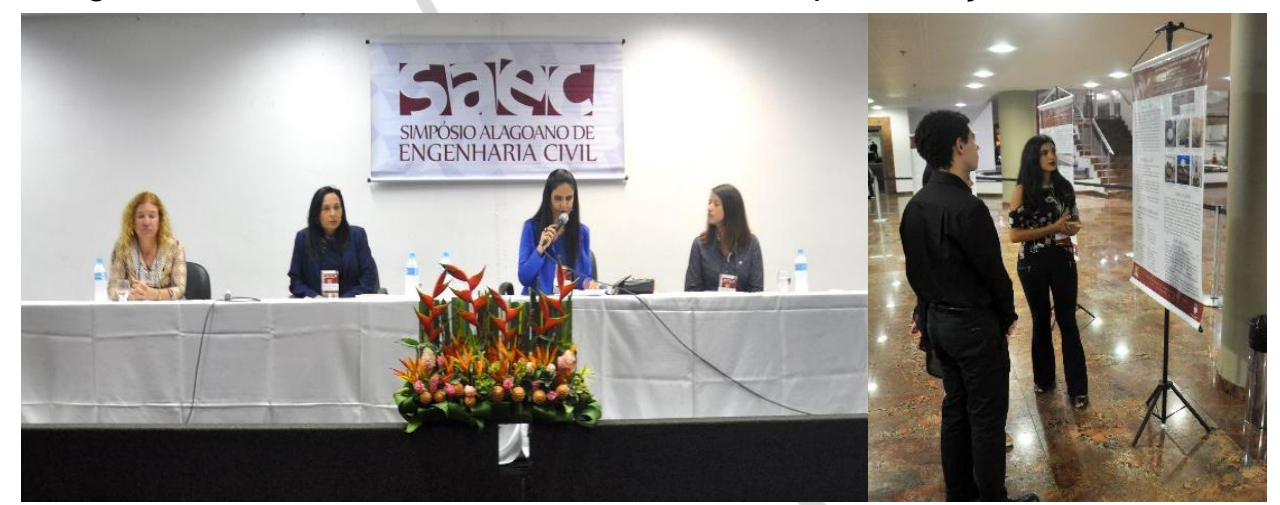

Fonte: Autores (2017)

Toda a organização por trás de um evento realizado por petianos (alunos de graduação integrantes do Programa de Educação Tutorial - PET Engenharia Civil) proporciona grandes contribuições não só ao Estado de Alagoas e aos participantes, mas principalmente aos organizadores, uma vez que enfrentam desafios durante a organização para proporcionar um evento de qualidade.

Ao longo de aproximadamente oito meses, os integrantes do PET Civil se dividem em cinco equipes executoras: financeiro, patrocínio, palestrantes, comunicação e infraestrutura. Dentro dessas equipes, os petianos são 
estimulados a lidar com situações em que a graduação por si só não seria capaz de proporcionar, como negociação com grandes empresas a fim de obter patrocínio para a realização do evento, lidar com questões orçamentárias e financeiras, entrar em contato com possíveis palestrantes do Brasil todo e utilização dos softwares de edição de imagens para elaboração de material gráfico como o Adobe Photoshop, CorelDRAW e Adobe Illustrator. Mais próximo da chegada do evento, as equipes se redividem e surgem equipes como inscrições e credenciamento, coffee-break e cerimonial.

A diversidade de atividades encaradas pela organização contribui para uma formação completa e diversificada do petiano, que além de se formar engenheiro, aprende a lidar com pessoas, gerenciar equipes e finanças, a organizar eventos, bem como falar em público para quem irá exercer a função de cerimonial.

\section{Conclusão}

Eventos e congressos, além de serem um benefício coletivo para a sociedade como um todo, em especial estudantes universitários e profissionais, proporcionam um desenvolvimento extra aos organizadores, no presente caso os petianos, envolvidos com seu planejamento e organização. É com essa visão que o PET Engenharia Civil da Universidade Federal de Alagoas realiza o SAEC há oito anos, com cada vez mais aderência de estudantes de Engenharia Civil das mais diversas instituições do estado e fora dele.

Como todo o evento é organizado pelos petianos, desde definição de temas para as palestras a questões financeiras e burocráticas, os membros do PET Engenharia Civil da UFAL são capacitados a tratar com situações que fogem do ambiente apenas acadêmico. Isso permite que todo o grupo seja capaz de aprender a lidar com assuntos e desafios que serão exigidos de certa forma no futuro, quando se tornarem profissionais. O que mais uma vez garante a excelência acadêmica de forma ativa.

\section{Referências}

GLANSO, F. R. C. Evento reúne aproximadamente $\mathbf{4 0 0}$ petianos do estado

de São Paulo. UNESP, São Paulo, mar. 2007. Disponível em: $<$ http://www.ibb.unesp.br/Home/Graduacao/ProgramadeEducacaoTutorialPET/sp pet ii.pdf>. Acesso em: 20 jan. 2018. 
MINISTÉRIO DA EDUCAÇÃO - MEC. Programa de Educação Tutorial - PET.

Manual de Orientações Básicas. Brasília, dez. 2006. 